\title{
Temporal Tillering Behavior of Sri Lankan Elite Rice Varieties in Response to PhosphorusAvailability
}

\author{
D.S. Kekulandara ${ }^{*}$, P.C.G. Bandaranayake ${ }^{1}$, D.N. Sirisena ${ }^{2}$ \\ W.L.G Samarasinghe ${ }^{3}$ and L.D.B. Suriyagoda ${ }^{4}$
}

Rice Research \& Development Institute

Batalagoda, Ibbagamuwa

Sri Lanka

\begin{abstract}
Tillering is closely related to environmental conditions including the accessibility to nutrients. Phosphorus $(P)$ availability affects tillering dynamics in rice. A hydroponic experiment was conducted to identify the tillering dynamics of forty eight elite rice varieties in response to optimum $(50 \mu M)$ and deprived $(10 \mu M) P$ status in the growing medium. Results showed that there was a significant delay in tillering in $P$ deprived condition. Days taken to tillering, shoot dry weight, root dry weight, growth rate, shoot $P$ concentration, $P$ uptake rate, $P$ utilization efficiency and shoot : root dry weight ratio at the time of tillering were affected by the variety and level of $P$ supply. There was no relationship between the time to initiate tillering and the age for maturity of a rice variety. The variety $B g$ 94-1showed least delay in tillering followed by Bg 454 and At 353 and they were identified as tolerant varieties while most of elite rice varieties were identified as susceptible rice varieties for $P$ deficiency tolerance. Furthermore, days taken for tillering can be used as a nondestructive criterion in selecting plants in segregating populations at early growth stages for P deficiency tolerance.
\end{abstract}

Keywords: Hydroponic culture, Phosphorus deficiency tolerance, Elite rice varieties

\section{INTRODUCTION}

Soil is the natural source of phosphorus $(\mathrm{P})$ for plants. A higher portion of $\mathrm{P}$ in soil presents in unavailable forms or not available closer to the rhizosphere (Holford, 1997).Available forms of $\mathrm{P}$ in soil are present in low concentrations, typically around $1-10 \mathrm{mM}$ in the soil solution (Hinsinger, 2001).Long term studies conducted at the Rice Research and Development Institute, Sri Lanka, revealed that yields of high yielding varieties remained at $2.5-3 \mathrm{t} / \mathrm{ha}$ in plots which did not receive chemical or any form of fertilizer. This suggests that the inherent soil fertility is not sufficient to maintain a high yield (Dhanapala, 2000). Phosphorus plays an important role in plant structural and functional processes, such as formation of cell membrane, synthesis and transfer of genetic material, respiration, photosynthesis, nutrient movement within the plant and cellular energy transfer (Wiedenhoeft, 2006: Abolfazli et al., 2012). Phosphorus deficiency mainly affects the shoot growth in rice resulting reduced tiller production, and reduced leaf elongation rate. The final

\footnotetext{
Agricultural Biotechnology Centre, Faculty of Agriculture, University of Peradeniya, Sri Lanka

Rice Research \& Development Institute, Batalagoda, Ibbagamuwa, Sri Lanka

Plant Genetic Resource Centre, Gannoruwa, Peradeniya, Sri Lanka

4 Department of Crop Science, Faculty of Agriculture, University of Peradeniya, Sri Lanka

* Author for correspondence: deepthikasaman@gmail.com
} 
result is reduction of the rice yield (Luquet et al., 2005). Therefore, it is necessary to maintain soil $\mathrm{P}$ availability to ensure rice productivity.

Heavy use of $\mathrm{P}$ fertilizers causes higher expense to farmers due to higher prices. It will increase the ecological risk as well causing eutrophication and Cadmium contamination in the environment (Smil, 2000; Hart et al., 2004). These problems can be minimized by developing $\mathrm{P}$ deficiency tolerant rice varieties asa sustainable, environmental friendly and profitable approach to increase the P-use efficiency for resource-poor farmers in Sri Lanka. The fundamental step in the varietal development process is the identification of donor parents for $\mathrm{P}$ deficiency tolerance among available germplasm. As rice varieties differ in their $\mathrm{P}$ requirements, varieties which grow well under a low $\mathrm{P}$ availability and respond well to added $\mathrm{P}$ are the most desirable to be used as donors (Fageria et al., 1998).A few attempts have been made in Sri Lanka to identify such germplasm, for examples, Kottearachchiand Wijesekara, (2013) found that the rice varieties $\mathrm{Bg} 352$, Bg359, At 405 and $\mathrm{Bg} 357$ are tolerant and At 354is susceptible phosphorus deficiency (PD) tolerant; in contrast Aluvihare et al., (2014) identified H4 and some other traditional varieties are PD tolerant and Bg 352, Bg357 and At 354 varieties as highly PD sensitive. Later, Aluvihareet al., (2016a) has reported $\mathrm{H} 4, \mathrm{H} 7, \mathrm{H} 10, \mathrm{Bg} 94-1, \mathrm{Bg} 403$ and At 362 as tolerant, $\mathrm{Bg} 352$ as moderately tolerant and $\mathrm{Bg} 357$, At 354, Bg300and At 306are susceptible varieties for PD tolerance. However, most of the selections are contradictory and some genotypes are traditional types or with undesirable morphological and agronomic characters. As a result, they are not suitable for novel rice breeding programmes. Therefore, identification of phosphorus deficiency (PD) tolerance in elite rice cultivars is essential to make rice breeding programs more efficient and successful.

Phosphorus deficiency will result in reduced shoot growth and lesser tiller production in rice plants (Luquet et al, 2005).Tiller number has been used as an indicator for evaluating $\mathrm{P}$ deficiency tolerance in rice cultivars (Fageria et al., 1998; Aluvihare et al., 2016a). However, studies are rare for studying delay in tillering in rice under low $\mathrm{P}$ availability.

The previous studies have assessed PD tolerance in rice germplasm based on destructive parameters except the count of tiller number and the plant height, but the number of days delayed in tillering under P deficiency condition compared with that under optimum P supply has not considered as a PD tolerance related parameter. The destructive parameters cannot be used in selecting individual plants in segregating populations in breeding programs aiming to improve PD tolerance in popular rice varieties.

Phosphorus deficiency tolerance can be measured directly based on dry weight gains or grain yield of a crop when grown in P deficient soils (Fageria et al., 1988). However, detailed assessment of plant responses to $\mathrm{P}$ nutrition is difficult in soil, as many other factors such as microbial activity and changes in soil $\mathrm{pH}$ which affect the $\mathrm{P}$ availability. Moreover, $\mathrm{P}$ responses in roots are difficult to detect in soil medium (Wissuwa, 2005). Therefore, hydroponic experiments will be more appropriate than experiments conducted in soil in this regard. Since P concentration could be controlled more accurately and data collection could be more accurate.

This study was conducted to screen Sri Lankan rice varieties for P deficiency tolerance in hydroponic system. 


\section{MATERIALS AND METHODS}

Experiment was conducted in a plant house at the Agricultural Biotechnology Center, University of Peradeniya, Sri Lanka, from May to August 2015. Minimum and maximum temperatures during this period were $26^{\circ} \mathrm{C}$ and $38^{\circ} \mathrm{C}$, respectively.

Forty-five improved and three old improved rice varieties belonged to different maturity groups; short age (2.5 - 3months), medium age (3.5 months), and long age (4-4.5months) were evaluated in this study. All the rice varieties in short age group (Bg250, At 303, Bg 300 , At 307 etc.) were improved rice varieties. Except H7, all other 18 rice varieties $(\mathrm{Bg} \mathrm{366}$,

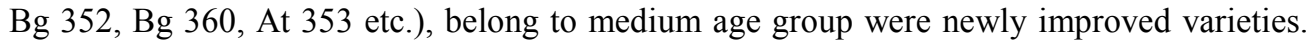
Two varieties (H10 and $\mathrm{H} 4)$ in long age group were old improved while all the other varieties (Bg 455, Bg 450, Bw 400, At 405 etc.) were new improved varieties (Table1).

Table1. Type and age group of rice varieties screened

\begin{tabular}{lll}
\hline Age group & New improved varieties & Old improved varieties \\
\hline Short age & Bg 250, Bg 300, Bg 304, Bg 305, - \\
& Bg 310, Bw 272-6B, At 303, At 306, \\
(2.5-3 months) & At 307, At 308 \\
\hline Medium age & Bg 366, Bg 352, Bg 369, Bg 360, H7 \\
& Bg 357, Bg 358, Bg 94-1, Bw 361, \\
(3.5 months) & Bg 359, Bw 364, Bw 363, Bw 351, \\
& Bw 367, At 353, At 354, At 362, Ld \\
& 368, Ld 365 \\
\hline Long age & Bg 380, Bg 403, Bg 406 Bg 450, Bg H4, H10 \\
& $454, \mathrm{Bg} \mathrm{455,} \mathrm{Bg} \mathrm{379-2,} \mathrm{Bg} \mathrm{400-1,}$ \\
& Bg11-11, Bw 400, Bw 451, \\
& Bw 452, Bw 453, At 401, At 402, \\
& At 405, Ld 408
\end{tabular}

Seeds of all the varieties were soaked in water for $24 \mathrm{~h}$ and germinated in moist tissue papers in petri dishes. Seven days after seeding, seedlings were planted in plastic buckets filled with Yoshida nutrient solution (Yoshida et al., 1976) supplemented with either, $50 \mu \mathrm{M}$ of $\mathrm{P}$ (optimal) or $10 \mu \mathrm{M} \mathrm{P}$ (deprived) concentrations. Each bucket contained $6.5 \mathrm{~L}$ nutrient solution. Seedlings were placed in the holes made in Styrofoam plate using sponge stripes. Six seedlings were placed as replicates in one bucket at a similar spacing (Plate 01). 


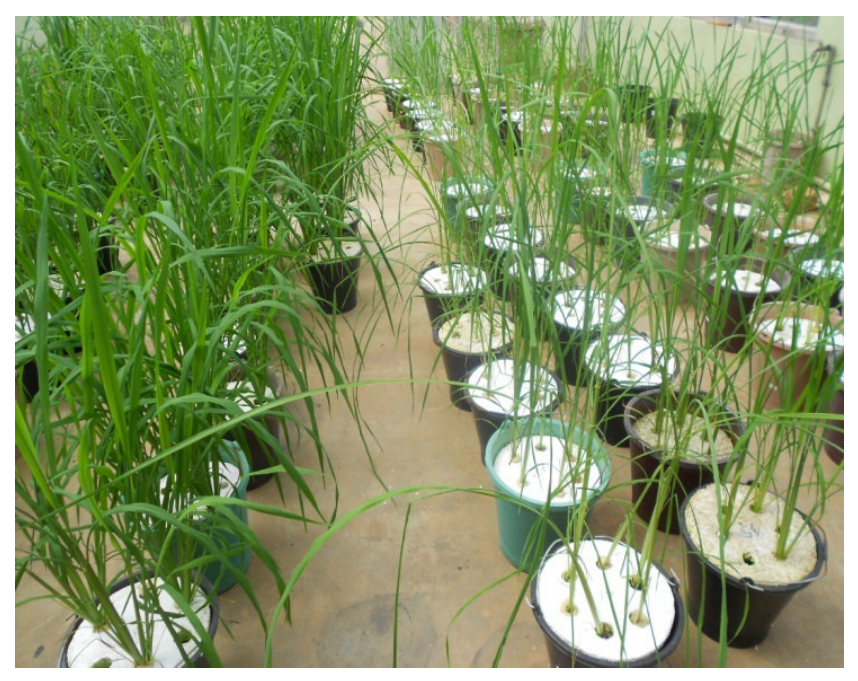

\section{Plate 1. Plants in the green house at 40 days of age}

Growth medium was maintained at $\mathrm{pH}$ of 5.6-5.8 by adjusting $\mathrm{pH}$ in every 2 days and solution was replaced once a week. Design of the experiment was a Complete Randomized Design with 3 replicates and data collected were; days to tillering, shoot and root dry weight and shoot $\mathrm{P}$ concentration. At tillering stage of each variety, plants having only 2 tillers per plant were harvested. Shoots and roots of harvested plants were separated, oven dried at $80^{\circ} \mathrm{C}$ for $72 \mathrm{~h}$ and dry weights were measured.

\section{Plant analyses}

Shoot dry weight of plants in which tillering occurred before 52 days of age were measured. Five grams of each sample was ground and made into ash at $200{ }^{\circ} \mathrm{C}$ for $2 \mathrm{~h}$ followed by $450^{\circ} \mathrm{C}$ for $2 \mathrm{~h}$. The ash was dissolved in $6 \% \mathrm{HNO}_{3}$ and $\mathrm{P}$ concentrations were analyzed by colorimetric assay using the molybdovanadophosphate method with spectrophotometer (Kitson and Melon, 1944). Three samples with known standard P concentrations were analyzed in each set of samples.

The growth rate (total dry weight gain per day), shoot $\mathrm{P}$ content, shoot $\mathrm{P}$ uptake rate( amount of $\mathrm{P}$ content in the shoot per unit shoot dry weight per day), $\mathrm{P}$ utilization efficiency (Shoot dry weight produced per unit shoot $\mathrm{P}$ content) and the shoot:root dry weight ratio were calculated using the following formula.

Growth rate $(G R)=\frac{\text { Total dry weightof the plant }(g)}{\text { Ageof the plant }(\text { days })}$

Shoot $P$ Content $(S P C)=$ Shoot $P$ concentration $\times$ Shoot dry weight $(S D W)$

$P$ uptake rate $(P U R)=\frac{S P C}{S D W \times \text { Age of the plant }}$ 
Putilization efficiency $(P U E)=\frac{S D W}{S P C}$

Shoot: Rootdryweightratio $(S:$ Rratio $)=\frac{S D W}{\text { RootdryWeight }}$

\section{Data analysis}

Data were statistically analyzed using Proc GLM in SAS. To analyze the correlation between variables studied Proc CORR was used. A regression analysis was performed to understand the differential responses of varieties under low $\mathrm{P}$ availability in comparison to optimum $\mathrm{P}$ availability.

\section{RESULTS AND DISCUSSION}

Tillering is a major determinant of grain yield of rice (Gallagher and Biscoe, 1978), and it is affected by environmental conditions (Yoshidaet al., 1981).The environmental effect on tillering was minimized by conducting this study in a greenhouse using hydroponic culture.

There was a significant effect of $\mathrm{P}$ level in the medium and their interactions on days to tillering, shoot dry weight, root dry weight, growth rate, shoot $\mathrm{P}$ concentration, PUE and shoot: root dry weight ratio at early tillering stage except the parameter, shoot $p$ content. This is confirmed by the mean values given for relevant parameters (Table 3). Variety affects all the parameters studied (mean values are not given) and it reveals that parameters are varietal dependent (Table 2). Although P level and the variety affect the PUR, there is no significant effect of variety $\mathrm{P}$ level interaction (Table 2). Meanwhile, although there is a significant effect of variety on shoot $\mathrm{P}$ content, it is independent from the level of $\mathrm{P}$ supplied, but the interaction of variety and the P level shows an effect on SPC. It confirms that some varieties perform well under specific $\mathrm{P}$ levels.

Table2. Level of significance of variables studied

\begin{tabular}{llllllllll}
\hline & $\begin{array}{l}\text { DFT } \\
(\mathbf{d})\end{array}$ & $\begin{array}{l}\text { SDW } \\
(\mathbf{g})\end{array}$ & $\begin{array}{l}\text { RDW } \\
(\mathbf{g})\end{array}$ & $\begin{array}{l}\text { GR } \\
(\boldsymbol{\mu g} / \mathbf{g}\end{array}$ & $\begin{array}{l}\text { SP } \\
\text { Conc }\end{array}$ & $\begin{array}{l}\text { SPC } \\
(\boldsymbol{\mu g})\end{array}$ & $\begin{array}{l}\text { PUR } \\
(\boldsymbol{\mu g} / \mathbf{g} /\end{array}$ & $\begin{array}{l}\text { PUE } \\
\mathbf{( g / \mu g}\end{array}$ & $\mathbf{S : R}$ \\
$\mathbf{P})$ & \\
\hline Variety & $<0.01$ & $<0.01$ & $<0.01$ & $<0.01$ & $<0.01$ & $<0.01$ & 0.001 & $<0.01$ & $<0.01$ \\
P level & $<0.01$ & $<0.01$ & $<0.01$ & $<0.01$ & $<0.01$ & 0.339 & $<0.01$ & $<0.01$ & $<0.01$ \\
$\quad \begin{array}{c}\text { Variety } \\
\quad<0.01\end{array}$ & $<0.01$ & $<0.01$ & $<0.01$ & 0.013 & 0.004 & 0.067 & $<0.01$ & $<0.01$ \\
$\begin{array}{c}\mathbf{x} \\
\text { P level }\end{array}$ & & & & & & & & & \\
\hline
\end{tabular}

Legend: DFT-Days for tillering, SDW- Shoot dry weight, RDW -Root dry weight, GR-Growth rate, SPConc Shoot $\mathrm{P}$ concentration, SPC-Shoot P content, PUR - P uptake rate, PUE- P utilization efficiency, S:R - Shoot: root Dry weight ratio. 
Table 3. Mean values of parameters studied in $P$ supplied (+P) and $P$ deprived (-P) conditions at the time of tillering

\begin{tabular}{|c|c|c|c|c|c|c|c|c|c|}
\hline Parameter & $\begin{array}{l}\text { DFT } \\
\text { (d) }\end{array}$ & $\begin{array}{l}\text { SDW } \\
\text { (g) }\end{array}$ & $\begin{array}{l}\text { RDW } \\
\text { (g) }\end{array}$ & $\begin{array}{l}\text { GR } \\
(\mathrm{g} / \mathrm{d})\end{array}$ & $\begin{array}{l}\text { SPConc } \\
(\mu \mathrm{g} / \mathrm{g})\end{array}$ & $\begin{array}{l}\text { SPC } \\
(\mu g)\end{array}$ & $\begin{array}{l}\text { PUR } \\
(\mu \mathrm{g} / \mathrm{g} / \mathrm{d} \\
)\end{array}$ & $\begin{array}{l}\text { PUE } \\
(\mathrm{g} / \mu \mathrm{gP})\end{array}$ & S:R \\
\hline$+\mathrm{P}$ & $\begin{array}{l}20 \\
\pm \\
0.302\end{array}$ & $\begin{array}{l}0.12 \\
\pm \\
0.008\end{array}$ & $\begin{array}{l}0.024 \\
\pm \\
0.002\end{array}$ & $\begin{array}{l}0.007 \\
\pm \\
0.0003\end{array}$ & $\begin{array}{c}6184 \\
\pm \\
144.7\end{array}$ & $\begin{array}{l}743 \\
\pm \\
49.4\end{array}$ & $\begin{array}{l}1726 \\
\pm \\
63.4\end{array}$ & $\begin{array}{l}0.17 \\
\pm \\
0.004\end{array}$ & $\begin{array}{l}5.5 \\
\pm . \\
123\end{array}$ \\
\hline$-P$ & $\begin{array}{l}35 \\
\pm \\
0.802\end{array}$ & $\begin{array}{l}0.46 \\
\pm \\
0.031\end{array}$ & $\begin{array}{l}0.266 \\
\pm \\
0.022\end{array}$ & $\begin{array}{l}0.019 \\
\pm \\
0.001\end{array}$ & $\begin{array}{l}1624 \\
\pm \\
123.8\end{array}$ & $\begin{array}{l}613 \\
\pm \\
42.1\end{array}$ & $\begin{array}{l}127 \\
\pm \\
16.6\end{array}$ & $\begin{array}{l}0.91 \\
\pm \\
0.056\end{array}$ & $\begin{array}{l}2.1 \\
\pm \\
0.057\end{array}$ \\
\hline
\end{tabular}

For legend see Table 1.

\pm Standard error

Interaction between time taken for tillering and other parameters at low and high $P$ levels

There was a strong positive correlation between the days to initiate tillering and shoot and root dry weight at both high and low P levels (Tables 4 \& 5). At late tillering both shoot and root dry weights were higher than that of early tillering varieties despite the $\mathrm{P}$ availability.

Similarly there was a strong positive correlation between days to initiate tillering and growth rate at low $\mathrm{P}$ level than that at high $\mathrm{P}$ level (Tables 4 \& 5).

There was a negative relationship between the days toinitiatetillering and shoot $\mathrm{P}$ concentration at $\mathrm{P}$ deprived condition while such a relationship was not found at optimum $\mathrm{P}$ supply. Therefore, $\mathrm{P}$ concentration of plant tissues may be one of the factors influencing the initiation of tillering in rice. This confirms that tillering is a $\mathrm{P}$ nutrition related physiological process in rice.

Shoot $\mathrm{P}$ content also had significant positive correlation with days to initiate tillering at both $\mathrm{P}$ levels.There was a strong negative relationship with $\mathrm{P}$ uptake rate and days to initiate tillering at $\mathrm{P}$ deprived condition than that at high $\mathrm{P}$ condition, despite both relationships were significant (Tables $4 \& 5$ ). This indicates that $\mathrm{P}$ uptake rate has an influence on tiller initiation, and therefore, varieties with lesser $\mathrm{P}$ uptake rate will take more time to initiate tillering, confirming that tillering is a $\mathrm{P}$ nutrition related process in rice.

There was a significant positive relationship between the days to initiate tillering and P-use efficiency in both high and low P levels.

Correlation between days to initiate tillering and shoot:root ratio was negative only under low-P condition while such a correlation was not present at high $\mathrm{P}$ condition(Tables $4 \& 5$ ). It proves that at low $\mathrm{P}$ availability, shoot: root ratio has an effect on tillering of rice. 
Table 4. Correlation coefficients among the parameters at deprived $P$ condition (10 $\mu M)$ at the time of tillering

\begin{tabular}{|c|c|c|c|c|c|c|c|c|c|}
\hline & SDW & RDW & DFT & GR & SPConc & SPC & PUR & PUE & S:R \\
\hline SDW & 1.00 & $0.96^{*}$ & $0.83^{*}$ & $0.99^{*}$ & $-0.41^{*}$ & $0.56^{*}$ & $-0.46^{*}$ & $0.34^{*}$ & $-0.57^{*}$ \\
\hline$\overline{\text { RDW }}$ & & 1.00 & $0.82^{*}$ & $0.97^{*}$ & $-0.40^{*}$ & $0.50^{*}$ & $-0.45^{*}$ & $0.37^{*}$ & $-0.70^{*}$ \\
\hline DFT & & & 1.00 & $0.79^{*}$ & $-0.45^{*}$ & $0.53^{*}$ & $-0.62^{*}$ & $0.36^{*}$ & $-0.68^{*}$ \\
\hline GR & & & & 1.00 & $-0.43^{*}$ & $0.52^{*}$ & $-0.46^{*}$ & $0.36^{*}$ & $-0.62^{*}$ \\
\hline $\begin{array}{l}\text { SP } \\
\text { Conc }\end{array}$ & & & & & 1.00 & $0.29^{*}$ & $0.89^{*}$ & $-0.74^{*}$ & $0.44^{*}$ \\
\hline SPC & & & & & & 1.00 & 0.003 & $-0.41^{*}$ & $-0.24^{* *}$ \\
\hline PUR & & & & & & & 1.00 & $-0.53^{*}$ & $0.60^{*}$ \\
\hline PUE & & & & & & & & 1.00 & $-0.39^{*}$ \\
\hline S:R & & & & & & & & & 1.00 \\
\hline
\end{tabular}

For legend see Table 2

*, ** Significant at $\mathrm{P}=0.01$ and $\mathrm{P}=0.05$ respectively

Table 5. Correlation coefficients among the parameters at Optimum P (50 $\mu \mathrm{M})$ condition

\begin{tabular}{|c|c|c|c|c|c|c|c|c|c|}
\hline & SDW & RDW & DFT & GR & $\begin{array}{l}\text { SP } \\
\text { Conc }\end{array}$ & SPC & PUR & PUE & S:R \\
\hline SDW & 1.00 & $0.97^{*}$ & $0.70^{*}$ & $0.91^{*}$ & -0.12 & $0.86^{*}$ & $-0.24^{*}$ & $0.19^{*}$ & -0.11 \\
\hline RDW & & 1.00 & $0.67^{*}$ & $0.90^{*}$ & -0.14 & $0.81^{*}$ & $-0.37^{*}$ & $0.21^{*}$ & $-0.30^{*}$ \\
\hline DFT & & & 1.00 & $0.39^{*}$ & -0.02 & $0.48^{*}$ & $-0.22^{*}$ & $0.15^{* *}$ & -0.01 \\
\hline GR & & & & 1.00 & -0.09 & $0.91^{*}$ & $-0.23^{*}$ & 0.10 & $-0.18^{* *}$ \\
\hline $\begin{array}{l}\text { SP } \\
\text { Conc }\end{array}$ & & & & & 1.00 & $0.27^{*}$ & $0.69^{*}$ & $-0.89^{*}$ & 0.10 \\
\hline SPC & & & & & & 1.00 & 0.03 & $-0.21^{*}$ & -0.06 \\
\hline PUR & & & & & & & 1.00 & $-0.62^{*}$ & $0.72^{*}$ \\
\hline PUE & & & & & & & & 1.00 & -0.07 \\
\hline S:R & & & & & & & & & 1.00 \\
\hline
\end{tabular}

For legend see Table 2

*, **Significant at $\mathrm{P}=0.01$ and $\mathrm{P}=0.05$ respectively

\section{Interaction between days to initiate tillering at high and low P levels:}

Shoot and root dry weight can be used as selection criterion for varietal screening of $\mathrm{P}$ deficiency tolerance studies of rice (Fageria et al., 1988). However, this study shows that the parameter days to initiate tillering was highly significant with $\mathrm{P}$ level in the medium confirming it as another parameter to be used in varietal screening for P efficiency. Studying the days to tillering is easier and non-destructive. Therefore, this criterion can be used to select individual plants from segregating populations in breeding programs for introgression of novel gene in to a particular variety.

Out of the 48 varieties used only 32 varieties tillered during the 52 days of experimental period, while other varieties remained asa single main tiller (Table 6). When number of days taken for tillering at low and high $\mathrm{P}$ level was considered, there was a vast difference in days taken to initiate tillering in low $\mathrm{P}$ condition than that at high $\mathrm{P}$ condition. Some varieties such as $\mathrm{Bg} 454, \mathrm{Bg} 406, \mathrm{Bg} 11-11$ and $\mathrm{Bg} 400-1$ showed early tillering regardless of their respective age group in both $\mathrm{P}$ deprived and optimal conditions (Table 6 ). It proved that there is no relationship between the time to initiate tillering and maturity age of a rice variety. This 
finding indicates that the delay in tillering is mainly affected by $\mathrm{P}$ availability for the rice plant. Therefore, the days taken for initiation of tillering at low $\mathrm{P}$ condition can be considered as an indicator for P deficiency tolerance in rice varieties.

In this context, plotted scattered diagram explains that few varieties such as $\mathrm{Bg} 94-1, \mathrm{Bg} 454$ and At 353 showed lesser deviation from 1:1 line, reflecting that they are lesser P responsive (Fig 1). Therefore, those varieties can be selected as P deficiency tolerant in terms of tillering. Furthermore, varieties which did not tiller until 52 days of age at $\mathrm{P}$ deprived condition; including At 303, At 307, Bg 357, At 306, Bw 272-6b, Bw 364, Bw 351, Bg 358, $\mathrm{Bw}$ 367, Bw 453, H10, Bg 380, H4 and At 402, but they tillered before 22 days at optimum $\mathrm{P}$ availability. Out of them except $\mathrm{Bg} 359, \mathrm{Bg} 455$, At362 and $\mathrm{H} 7$ all other varieties tillered before 22 days at optimum $\mathrm{P}$ condition. Therefore it is not possible to select a few varieties as most $\mathrm{P}$ deficiency susceptible varieties, all the varieties did not tillered until 52 days can be considered as PD susceptible.

In a previous study conducted in pots filled with low nutrient soil and a field experiment in the same soil, Aluvihare et al., (2016a) reported that the Bg94-1 is a P deficiency tolerant variety using plant height, shoot dry weight, number of tillers, shoot $\mathrm{P}$ concentration and PUE as selective parameters. Although At 353 was identified as a tolerant variety in the present study it was identified as a 'moderately tolerant' variety by Aluvihare et al. (2016a). $\mathrm{H} 4, \mathrm{H} 10, \mathrm{H} 7, \mathrm{Bg} 403$ and At362 could not be identified as tolerant according to tillering behavior in the present experiment as they delayed tillering for more than 20 days in deprived $\mathrm{P}$ availability compared to optimum $\mathrm{P}$ supply though they were reported as PD tolerant varieties in early studies (Aluvihare et al., 2016a).

Table 6. Days taken by varieties for tillering in $P$ supplied and deprived conditions

\begin{tabular}{|c|c|c|}
\hline $\begin{array}{l}\text { Days taken to } \\
\text { tillering after } \\
\text { planting }\end{array}$ & $\begin{array}{c}\text { At High P } \\
(50 \mu \mathrm{M})\end{array}$ & $\begin{array}{c}\text { At Low P } \\
(10 \mu M)\end{array}$ \\
\hline $17-22$ & 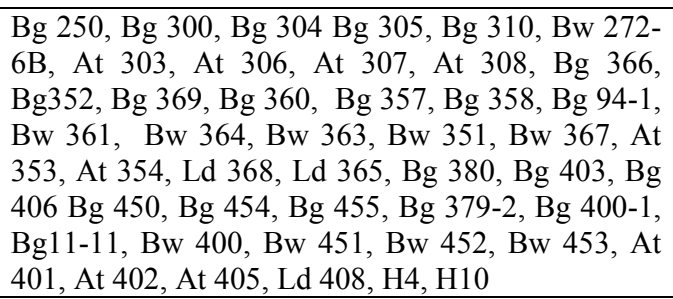 & Bg 94-1, Bg 454, At 353 \\
\hline $23-28$ & Bg359, Bg455, At362 & \\
\hline $29-34$ & - & $\begin{array}{l}\text { Bg 305, Bg 304, Bg 360, } \\
\text { At 354, LD 368, Bg 11-11, } \\
\text { Bw 400, At 405, Bg 400-1, } \\
\text { Bg 406, Bw 451, At 401 }\end{array}$ \\
\hline $35-40$ & $\mathrm{H} 7$ & $\begin{array}{l}\text { Bg 310, Bw 363, Ld 365, } \\
\text { Bw 361, Bg 450, Ld 408, } \\
\text { Bw 452, Bg 403 }\end{array}$ \\
\hline $41-46$ & - & $\begin{array}{l}\text { Bg 250, Bg 300, At 308, } \\
\text { Bg 366, Bg 352, Bg 369, } \\
\text { Bg 359, Bg 455, Bg 379-2 }\end{array}$ \\
\hline
\end{tabular}




$\begin{array}{ll}\text { Not tillered }- & \text { At 303. At 307, At 306, } \\ & \text { Bw 272-6b, Bw 364, Bw } \\ & 351, \text { At 362, Bg 357, Bg } \\ & 358, \text { Bw 367, Bw 453, } \\ \text { H10, Bg 380, H4, At 402, } & \text { H7 }\end{array}$

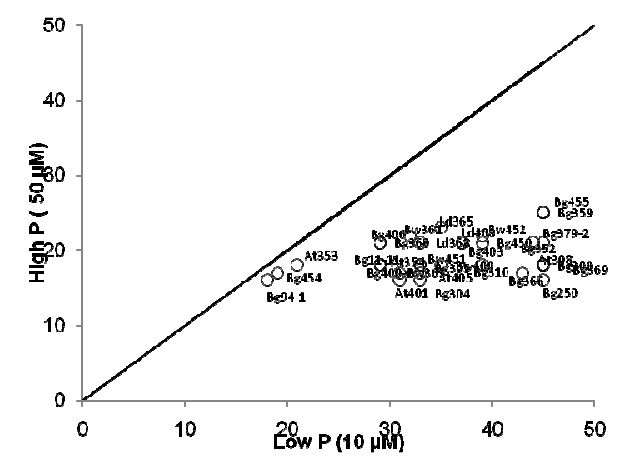

Fig. 1. Relationship between days to tillering at low $(10 \mu M)$ and high $(50 \mu M)$ phosphorus levels

According to Aluvihare (2016), presence of 433bp allele of K46-K2 DNA marker is strongly associated with PD tolerance and in Bg94-1 and At 353 rice varieties this allele was absent. Moreover, Aluvihare (2016) reported that absence of 130 bp allele in K46-CG2 marker denotes PD tolerant varieties, but in both $\mathrm{Bg} 94-1$ and At 353 rice varieties this allele is present. It reveals that Bg94-1 and At353do not have the Pup1 QTL in their genome to possess the PD tolerance. Therefore studies should be carried out to investigate the genes involving P deficiency in these varieties. It may be the same gene or QTL as Bg94-1 is one of the parents of At353.

Dee-Geo-Woo-genis a high-yielding, heavy-tillering and short-statured Chinese variety (Hargrove and Coffman, 2006).It is one of the ex-parents of Bg94-1 variety (Table 7). Inheritance of characters ofDee-Geo-Woo-genmay be the cause for P deficiency response in tillering in Bg94-1.

MR1523, a parent of $\mathrm{Bg} 454$ is a brown plant hopper resistant rice variety. There is no evidence of PD tolerance in this variety or its other parents. Therefore investigations should be carried out to exploit the responsible genes or QTLs in future studies.

Table 7. Parentage of selected varieties for PD tolerance

\begin{tabular}{lll}
\hline Tolerant variety & P1 & P2 \\
\hline Bg 94-1 & IR 262 & Ld66 \\
& (PETA/IR95) & (H-501/Dee-Geo-Woo-gen) \\
Bg 454 & MR 1523 & $87-519$ \\
& & $(83-1012 /$ Bg379-2) \\
At 353 & Bg 94-1 & Bg 400-1 \\
& (IR 262/Ld66) & (Ob 678//IR 20/H4) \\
\hline
\end{tabular}

P1- Female parent of selected varieties, P2 - Male parent of the selected varieties, within parenthesis - parents of particular line or variety 


\section{CONCLUSION}

Time taken to initiate tillering was affected by the variety and $\mathrm{P}$ concentration in the growth medium. In low $\mathrm{P}$ hydroponic culture days taken for tillering was inversely related with shoot $\mathrm{P}$ concentration and $\mathrm{P}$ uptake rate indicating the requirement of $\mathrm{P}$ for tiller initiation. Thereby days taken for tillering can be used as an easy, early and non- destructive method for screening germplasm and selecting individual plants in segregating populations of $P$ deficiency tolerant varietal improvement programs. Considering the time taken to initiate tilleringunder $\mathrm{P}$ deprived condition Bg94-1, Bg454 and At353 can be considered as $\mathrm{P}$ deficiency tolerant genotypes while most of other varieties are susceptible for PD tolerance.

\section{ACKNOWLEDGEMENT}

Authors are grateful to the National Science Foundation for giving financial support for this study (Grant number NSF/2014/AG/01). Thanks are due to Mr. Gemunu Wijesuriya for technical assistance and the staff members of Agricultural Biotechnology Centre, University of Peradeniya for the support given for conducting greenhouse experiment.

\section{REFERENCES}

Abolfazli, F., Forghani, A. and Norouzi, M. (2012).Effects of phosphorus and organic fertilizers on phosphorus fractions in submerged soil.J. Soil Sci. Plant Nutr, 12(2), 349 - 362

Aluwihare, Y.C., Lelwala R, Ishan, M., Sirisena, D.N., Samarasinghe, W.L.G., Sooriyapathirana, S.D.S. S.(2014). Screening of Sri Lankan rice varieties under nonphosphate fertilizer condition.[Online].[Accessed on 10.02.2016].Availableat [https://www.researchgate.net/publication/283298402_Screening_of_selected_Sri_Lankan_ri ce_varieties_under_non-_phosphate_fertilizer_condition.

Aluwihare, Y.C., Ishan, M., Chamikara, M.D.M., Weebedde, C.K, Sirisena, D.N., Samarasinghe, W.L.G., Sooriyapathirana, S.D.S.S.(2016a). Characterization and selection of phosphorus deficiency tolerant rice genotypes in Sri Lanka. RiceScience. 23, 184 - 195

Aluwihare, Y.C. (2016).Identification of the genomic regions associated with phosphorus deficiency tolerance in Sri Lankan rice germplasm for marker assisted breeding. UnpublishedPh.D theses. Postgraduate Institute of Science, University of Peradeniya. 94-95

Dhanapala, M.P. (2000). Bridging the rice yield gap in Sri Lanka.[On line].[Accessed on 07.03.2016].Available at http://www.fao.org/docrep/003/x6905e/x6905e0c.htm.

Fageria, N.K, Wright, R.J., Baligar, R.C., (1998).Cultivar evaluation for phosphorus use efficiency. Plant and Soil 111, 105 - 109

Gallagher, J.N., Biscoe, P.V. (1978). Radiation absorption, growth and yield of cereals.Journal of Agricultural Science. 91, 47 - 60

Hargrove,T. andCoffman, W. R,(2006). Breeding history. Rice Today October-December $2006,35-38$ 
Hart, M.R., Quin, B.F, and Nguyen, M.L. (2004). Phosphorus runoff from agricultural land and direct fertilizer effects: A review. J. Environ. Qual. 33, 1954 - 1972

Holford, I.C.R. (1997). Soil phosphorus: its measurement, and its uptake by plants. Aust J Soil Res.35, 227 - 239

Hinsinger, P. (2001). Bioavailability of soil inorganic P in the rhizosphere as affected by root-induced chemical changes: a review.Plant and Soil 237, 173 - 195

Kitson, R.E., Melon, M.G. (1944). Colorimetric determination of phosphorus as molybdovanadophosphoric acid.IndEngChem Anal Ed 16:379

Kottearachchi, N.S. and Wijesekara, U.A.D.S.L. (2013). Implementation of Pup 1 gene based markers for screening of donor varieties for phosphorus deficiency tolerance in rice. Indian J. Plant Sci.2(4), 76 - 83

Luquet, D., Zhang, B.G., Dingkuhn, M., Dexet, A.and Clement-Vidal, A. (2005). Phenotypic plasticity of rice seedlings: case of phosphorus deficiency. Plant Prod. Sci.8, 145 - 151

Smil, V. (2000). Phosphorus in the environment: natural flows and human interferences. Annu. Rev. Energy Environ. 25, 53 - 88

Yoshida, S, Forno, D.A.,Cock, J.H., Gmez, K.A. (1976).Laboratory manual for physiological studies of rice,IRRI, Manila, Pilippines.

Yoshida, S. (1981). Fundamentals of rice crop science. Los Baños,International Rice Research Institute. 269.

Wiedenhoeft, A.C. (2006). Plant Nutrition, Chelsea House Press, USA. 144 p

Wissuwa, M. (2005).Combining a modeling with a genetic approachin establishing associations between genetic and physiologicaleffects in relation to phosphorus uptake. Plant Soil, 269, 57 - 68. 